\title{
APLIKASI MODUL DIGITAL BERBASIS WEB RESPONSIVE PADA STIK BINA HUSADA
}

\author{
Tri Risqi Ariantoro' ${ }^{1}$ Arief Pamuji'2, Imam Solikin ${ }^{3}$ \\ 1,2STIK Bina Husada \\ 3Universitas Bina Darma \\ Jl. Syech A Somad No.28, Kota Palembang, Sumatera Selatan 30131 \\ email: 1tririsqiariantoro@yahoo.com, 2arief_bleck85@ymail.com, \\ 3imamsolikin@binadarma.ac.id
}

\begin{abstract}
Bina Husada College of Health is a private university in Palembang. The media used for lectures or teaching and learning still use modules or books (print media), and when in the classroom media are used projectors, blackboards. The problem that arises from this is that students will miss the material if students are unable to attend, when using a print module students must study in certain places to repeat the material even students are lazy to bring printed books. The solution that can be used to overcome these problems is to develop media that are used for teaching and learning process, namely digital media (digital modules). Digital modules are modules that are presented in electronic format. This research develops information technology in the form of responsive web-based digital modules to improve student learning at STIK Bina Husada Palembang. The purpose of this development is expected to help students who miss the material, making it easier for students in the learning process, because digital modules can be accessed and studied wherever the place is online using a smartphone. The digital module is a full digital module from the first meeting material to the final meeting. The application development method used is a linear sequential model with several stages, namely analysis, design, coding, testing, and support, while the data collection techniques used are observation, interview and documentation. The results of this research are in the form of responsive web-based digital module application at STIK Bina Husada Palembang.
\end{abstract}

Keywords: application, digital module, responsive web, linear sequential model

\section{Abstrak}

Sekolah Tinggi Ilmu Kesehatan (STIK) Bina Husada merupakan Perguruan Tinggi (PT) swasta yang ada kota palembang. Media yang digunakan untuk perkuliahan atau belajar mengajar masih menggunakan modul atau buku (media cetak), dan ketika di dalam kelas media yang digunakan proyektor, papan tulis. Permasalahan yang ditimbulkan dari hal tersebut adalah mahasiswa akan ketinggalan materi apabila mahasiswa berhalangan hadir, apabila menggunakan modul cetak mahasiswa harus belajaran ditempat tertentu untuk mengulang materi bahkan mahasiswa cedrung malas membawak buku cetak. Adapun solusi yang bisa digunakan untuk mengatasi masalah tersebut adalah dengan melakukan pengembangan media yang digunakan untuk proses belajar mengajar yaitu media digital (modul digital). Modul digital merupakan modul yang disajikan dalam format elektronik. Penelitian ini mengembangakan teknologi informasi berupa modul digital berbasis web responsive untuk meningkatkan belajar mahasiswa STIK Bina Husada Palembang. Tujuan dari pengembangan ini diharapkan untuk membantu belajaran mahasiswa yang 
ketinggalan materi, mempermudah mahasiswa dalam proses belajar, karena modul digital dapat diakses dan dipelajarin dimanapun tempatnya secara online menggunakan smartphone. Modul digital tersebut merupakan modul digital full dari materi pertemuan pertama sampai pertemuan akhir. Metode pengembangan aplikasi yang digunakan yaitu linier sequential model dengan beberapa tahapan yaitu analysis, design, coding, testing, dan support, sedangkan teknik pengumpulan data yang digunakan yaitu teknik observasi, wawancara dan dokumentasi. Hasil dari penelitian tersebut berupa aplikasi modul digital berbasis web responsive pada STIK Bina Husada Palembang.

Kata kunci: aplikasi, modul digital, web responsive, linier sequential model

\section{PENDAHULUAN}

Kemajuan teknogi informasi menuju industri 4.0 saat ini dapat diterapakan dalam dunia pendidikan untuk meningkatkan kualitas dan fasilitas di Perguruan Tinggi. Saat ini perguruan tinggi masih belum sepenuhnya memanfaatkan kemajuan teknologi informasi untuk meningkatkan fasilitas dalam mendukung pendidikan. Salah fasilitas Perguruan Tinggi (PT) yang akan dikembangkan berdasarkan kemajuan teknologi menuju industri 4.0 berupa modul digital yang merupakan transisi dari modul kovensional (modul cetak) menjadi modul digital. Modul digital atau e-modul merupakan dokumen atau artikel dalam format elektronik yang dapat dimanfaatkan untuk media belajar [1]. Pengembangan yang dilakukan juga harus sesuai dengan kemanjuan teknologi informasi saat ini yang lebih kearah smartphone. Smartphone merupakan telephone yang memiliki fiturfitur dengan kemanpuan melebihi telephone pada umumnya, seperti fasilitas pendukung tambahan aplikasi [2]. Smartphone sekarang ini bukan hanya digunakan sebagai media komunikasi tetapi juga dapat digunakan dan dimanfaatkan untuk mangakses fasilitas online yang ada di Perguruan Tinggi. Sehingga website yang dikembangkan untuk memenuhi kebutuhan perguruan tinggi juga cara harus bisa diakses secara maksimal melalui smartphone. Website responsive merupakn website yang bisa menyesuaikan tampilan layout ukuran viewport dari device yang digunakan mulai dari smartphone, tablet atau komputer screen [3].

Sekarang ini proses perkuliahan dalam perguruan tinggi masih banyak yang bersifat konvensional yaitu dalam menyampaikan materi perkuliahan kepada mahasiswa dengan menampilkan slide melalui Ms. Power Point ketika perkuliahan berlangsung atau mahasiswa mencetak atau membeli modul materi matakuliah. Kebiasaan mahasiswa di indonesia yang terkadang malas untuk mencatat materi yang disampaikan membuat mahasiswa kesulitan untuk memahami materi perkuliahan karena daya ingat mahasiswa terbatas. Dengan mencetak atau membeli modul bisa menjadi bebas dalam segi ekonomi dan terkadang mahasiswa juga malas membawa modul cetak dengan alasan berat, penggunakan modul cetak mudah mengalami kerusakan. Kekurang lain dalam belajar menggunakan modul cetak harus ditempat-tempat tertentu, lain halnya dengan menggunakan modul digital bisa diakses dan dipelajari melalui smartphone.

Permasalahan diatas terjadi juga Sekolah Tinggi Ilmu Kesehatan (STIK) Bina Husada yang masih menggunakan media konvensional seperti modul cetak

Aplikasi Modul Digital Berbasis Web Responsive Pada Stik Bina Husada (Tri Risqi Ariantoro)| $\mathbf{3 0 5}$ 
dalam aktifitas perkuliahan sehingga perlu dilakukan pengembangan media dalam perkuliahan dari media konvensional menjadi modul digital yang bisa diakses secara online oleh mahasiswa melalui smartphone. Modul digital juga bisa mengurangi beban ekonomi dalam membeli atau mencetak modul serta dapat meningkatkan minat dan hasil belajar mahasiswa. Kemudian bisa mempermudah mahasiswa STIK Bina Husada untuk mendapatkan materi perkuliahan yang diberikan dosen-dosen tanpa harus mencatat materi, modul digital tidak akan rusak dan mudah diakses dan dipelajari melalui PC (Personal Computer) ataupun smartphone.

Berdasarkan penjelasan diatas, maka perlu dilakukan penelitian lebih lanjut agar memotivasi dan minat belajar mahasiswa STIK Bina Husada meningkat. Penelitian yang dilakukan yaitu mengembangan aplikasi modul digital berbasis web responsive sebagai media pembelajaran alternatif STIK Bina Husada Palembang dengan metode pengembangan sistem yang digunakan linier sequential model, tahapan dari metode ini melalui analysis, design, coding, testing, and support. Aplikasi yang dikembangkan ini dapat mempermuda dalam mendapatkan materi dan memperlajarinya sehingga minat belajar mahasiswa STIK Bina Husada, dengan aplikasi modul digital berbasis web responsive menjadi meningkat.

Penelitian yang berkaitan dengan modul digital dilakukan oleh Suyasa dkk [4], yang membahas keterlibatan sumber daya manusia (SDM) dalam mendayagunakan teknologi open source dalam mempublikasikan modul digital. Penelitian lain yang digunakan untuk referensi dalam pengembangan modul digital yaitu penelitian yang dilakukan oleh Solikin [1], yang membahas tentang e-modul berbasis web mobile, Solikin \& Komalasari [5] membahas bahan ajar digital pada tingkat SLTA berbasis web, dan Purwaningtias \& Solikin [6] yang membahas tentang e-book pada tingkat SLTA berbasis web. Penelitian yang dilakukan oleh [1], [5] dan [6] digunakan sebagai referensi untuk meningkatkan media pembelajaran digital yang berupa modul digital. Pada pengembangan modul digital ini juga akan berikan notifikasi kapan modul harus di-update, agar modul digital yang di-upload tidak usang. Untuk penambahan fitur notifikasi peneliti menjadikan penelitian [7] dan [8] sebagai referansi.

Tujuan dari penelitian ini adalah untuk mempermudah siswa dan dosen dalam proses belajar mengajar melalui aplikasi modul digital dan untuk meningkatkan belajaran mahasiswa menjadi lebih baik.

\section{METODOLOGI PENELITIAN}

\subsection{Teknik Pengumpulan Data}

Teknik pengumpulan data merupakan langkah yang paling strategis dalam melakukan penelitian, karena tujuan dari penelitian adalah mendapatkan data untuk menghasilkan informasi yang berguna [9]. Metode penelitian yaitu cara ilmiah dalam mengumpulkan data untuk tujuan dan kegunaan tertentu [10]. Metode pengumpulan data yang digunakan dalam penelitian ini yaitu teknik observasi, teknik interview, dan teknik dokumentasi. 
a. Teknik observasi [11], Observasi yang dilakukan peneliti dengan langsung melihat proses pembelajaran pada STIK Bina Husada.

b. Teknik wawancara [12],

Wawancara dilakukan terhadap dosen STIK Bina Husada. Wawancara tersebut berupan, bagaimana proses belajaran pada STIK Bina Husada, media apa saja yang digunakan untuk fasilitas belajar mengajar pada STIK Bina Husada, dan permasalahan yang dihadapi dalam proses belajar mengajar pada STIK Bina Husada.

c. Teknik dokumentasi [13],

Data yang didapat dari teknik dokumentasi pada STIK Bina Husada yaitu data RPS dan data modul kuliahMenjelaskan kronologis penelitian termasuk cara menyiapkan bahan penelitian, rancangan atau desain penelitian, prosedur penelitian (dalam bentuk algoritma, pseudocode atau lainnya), cara pengujian dan pengambilan data. Pada bagian ini boleh juga diberikan dasar teori. Tabel dan Gambar dibuat center seperti di bawah ini dan diacu pada naskah.

\subsection{Metode Pengembangan Aplikasi}

Metode yang digunakan dalam pengembangan aplikasi adalah linier sequential model [14], tahapan dari metode ini melalui analysis, design, coding, testing, and support. Ilustrasi dari metode perkembangan aplikasi, dapat dilihat pada gambar 1 .

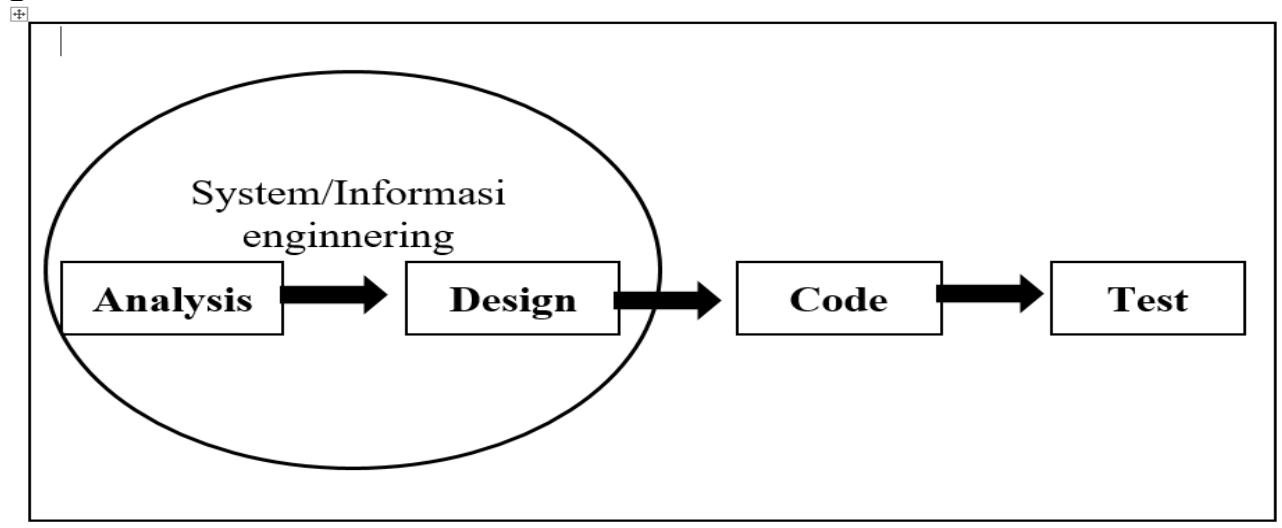

Gambar 1 Metode pengembangan aplikasi

a. Software requirements analysis,

Untuk melakukan analisa dilakukan pengumpulan data menggunakan teknik observasi, teknik wawancara, dan teknik dokumentasi yang dilakukan pada STIK Bina Husada.

b. Design,

Proses yang dilakukan pada tahap ini berupa perancangan modul digital berbasis web responsive pada STIK Bina Husada menggunakan usecase dan flowchart.

c. Code generation,

Pada tahap ini peneliti menerapkan desain kedalam koding menggunakan bahasa pemrograman berbasis web. Pada tahap ini menghasilkan aplikasi modul digital pada STIK Bina Husada berbasis web responsive. 
d. Testing,

Pada tahap ini dilakukan pengujian terhadap apliksi modul digital bebasis web responsive yang berhasil dijalankan.

e. Support,

Perubahan akan terjadi apabila kesalahan sudah ditemui. Aplikasi berbasis web responsive yang dibangun harus disesuaikan untuk mengakomodasi perubahan lingkungan eksternal dan perubahan yang diperlukan karena operasi baru sistem atau perangkat periferal, atau karena pelanggan memerlukan fungsional atau peningkatan kinerja

\section{HASIL DAN PEMBAHASAN}

\subsection{Desain Aplikasi Modul digital}

Aplikasi modul digital berbasis web responsive dirancangan menggunakan usecase [15], [16] dapat dilihat pada gambar 2. Perancangan aplikasi modul digital berbasis web responsive menggunakan flowchart [17] dapat dilihat pada gambar 3

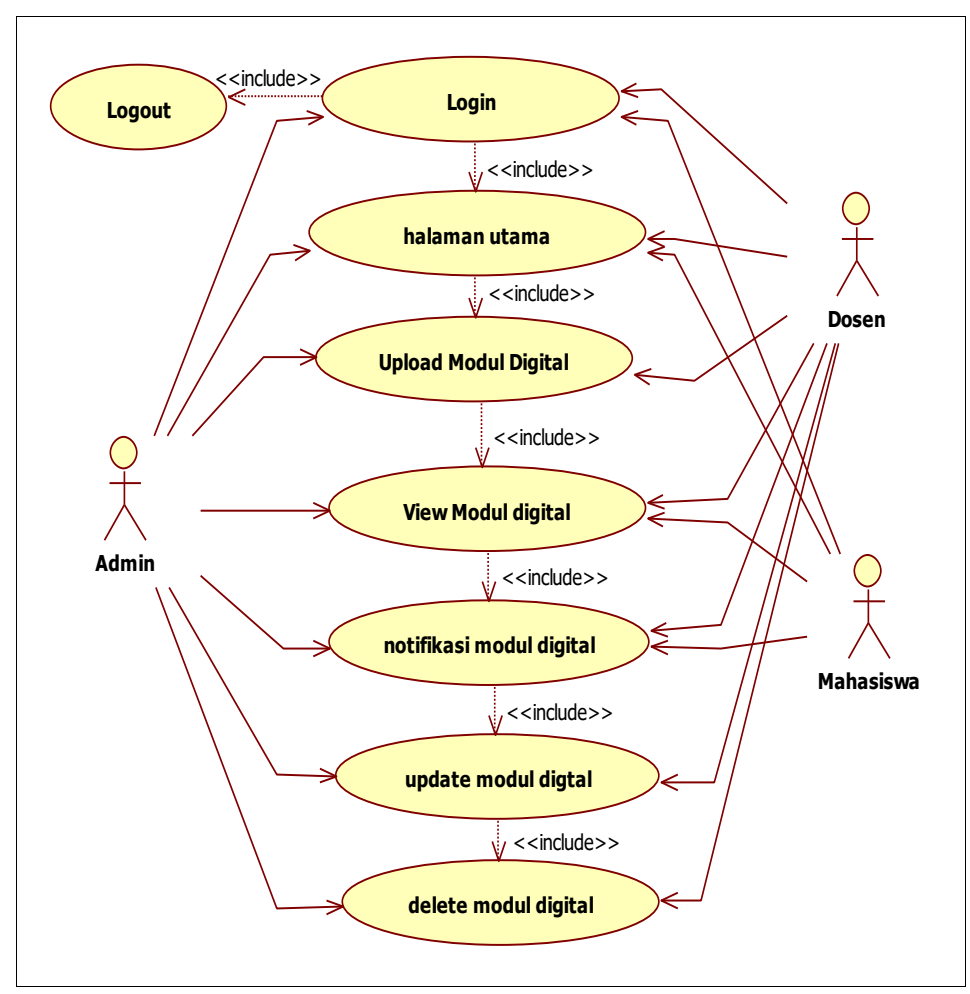

Gambar 2 Usecase aplikasi modul digital berbasis web responsive 


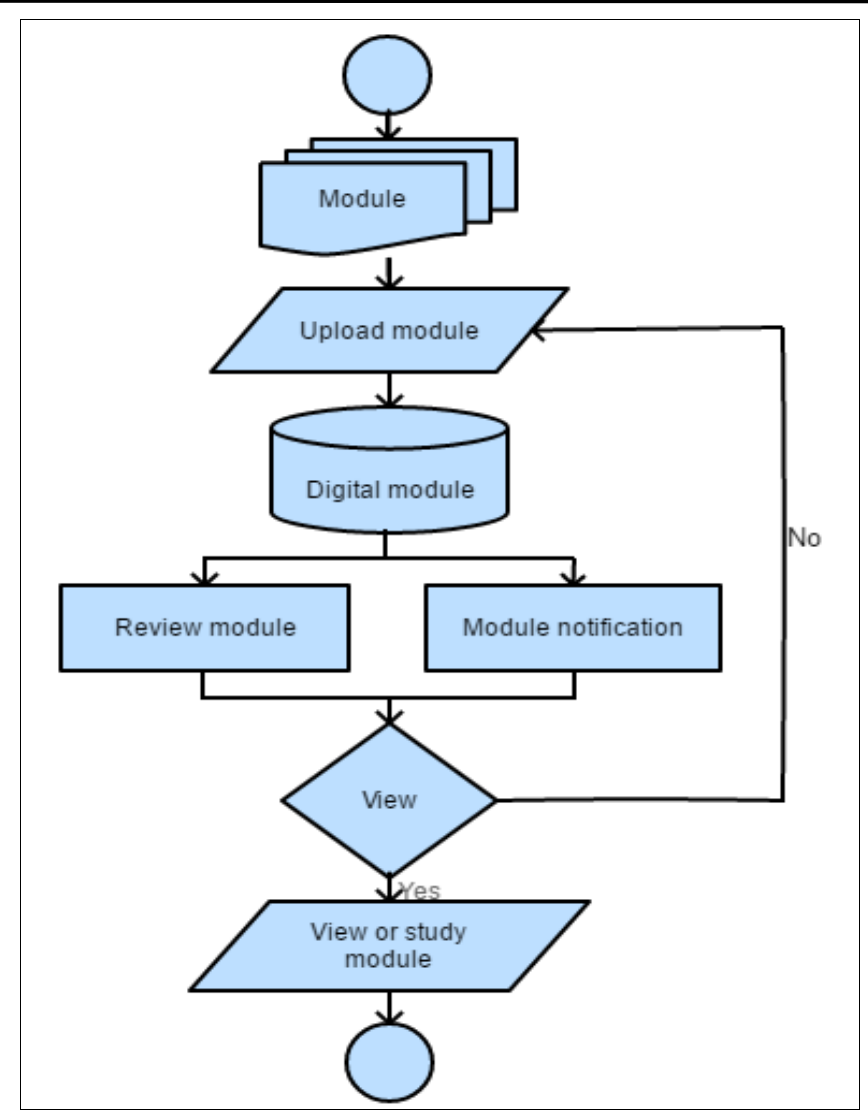

Gambar 3 Flowchart aplikasi modul digital berbasis web responsive

\subsection{Interface Aplikasi Modul Digital}

Setelah melalukan analisis dan desain dilanjukan dengan koding, yang menghasilkan aplikasi modul digital berbasis web responsive yang digunakan untuk media alternatif belajaran mahasiswa dan untuk meningkatkan minat belajar. Adapun interface yang dihasilkan adalah sebagai berikut.

a. Login

Login, merupakan halaman index dari suatu interface yang digunakan untuk masuk keaplikasi melalui hak akses yaitu username dan password. User yang mempunyai hak akses yaitu admin, dosen, dan mahasiswa sesuai dengan haknya akses, untuk menuju interface dashboard masing-masing. Adapun halaman login dapat dilihat pada gambar 4. 
b. Dashboard

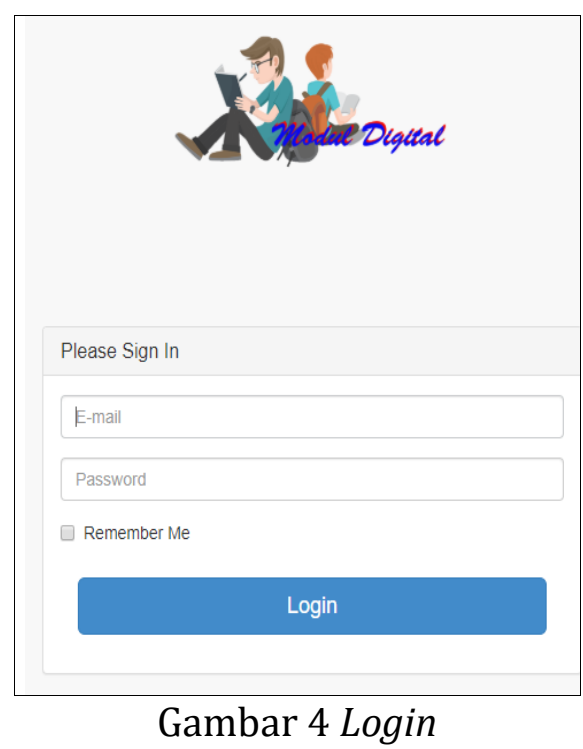

Dasboard, merupakan halaman utama yang muncul setelah user berhasil melakukan login. Setiap user mempuyai tampilan dashboard masing-masing. Pada dasboard admin terdapat beberapa menu antara lain menu program studi yang didalam terdapat sub-sub menu antara lain menu ilmu kebidanan, menu kesehatan masyarakat, dan menu ilmu keperawatan. Pada sub-sub menu tersebut berisi modul-modul digital yang dapat digunakan dalam proses belajar mahasiswa sesuai dengan prodi masing-masing. Interface dashboard admin dapat dilihat pada gambar 5 .

c. Dashboard mahasiswa dan dosen untuk menu program studi memunculkan tampilan modul-modul digital sesuai dengan progam studi homebase dari dosen dalam mengajar dan program studi mahasiswa. Tampilan dashboard dosen dan mahasiswa dapat dilihat pada gambar 6. Pada dashboard yang dapat dilihat gambar 6 ini mahasiswa dapat dengan mudah medapatkan materi dan mempelajari materi karena bisa diakses dengan smartphone.

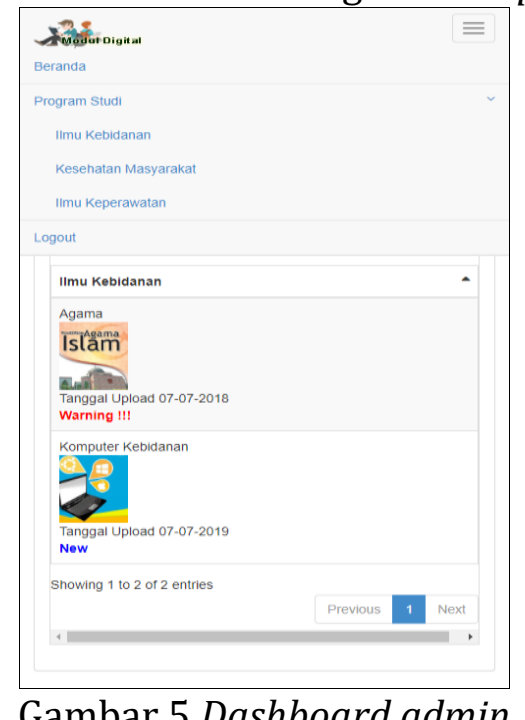

Gambar 5 Dashboard admin 


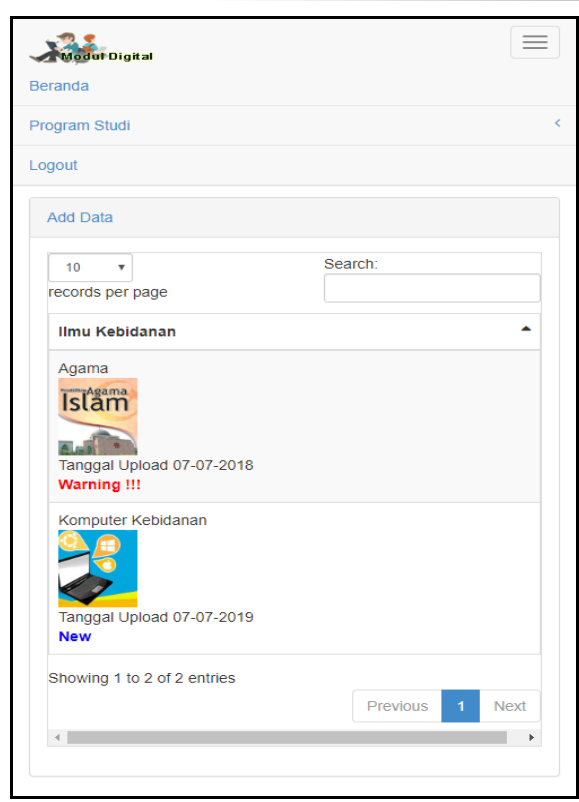

Gambar 6 Dashboard dosen dan mahasiswa

d. Daftar Modul Digital

Daftar modul digital, merupakan kumpulan dari modul-modul digital. Pada interface daftar modul digital pada admin dan dosen terdapat fasilitas add data yang digunakan untuk menambah modul digital, dan pemberitahuan pada modul digital (warning, repair, dan new). Berbeda dengan interface daftar modul digital mahasiswa tidak mempunyai fasilitas add data, hanya terdapat pemberitahuan pada (warning, repair, dan new). Pemberitahuan warning, repair, atau new merupakan pemberitahuan kapan modul digital tersebut harus di-update (warning), modul digital dalam masa tenggang untuk di-update (repair), dan modul tersebut masing baru di-update (new). Interface daftar modul digital dapat dilihat pada gambar 7 .

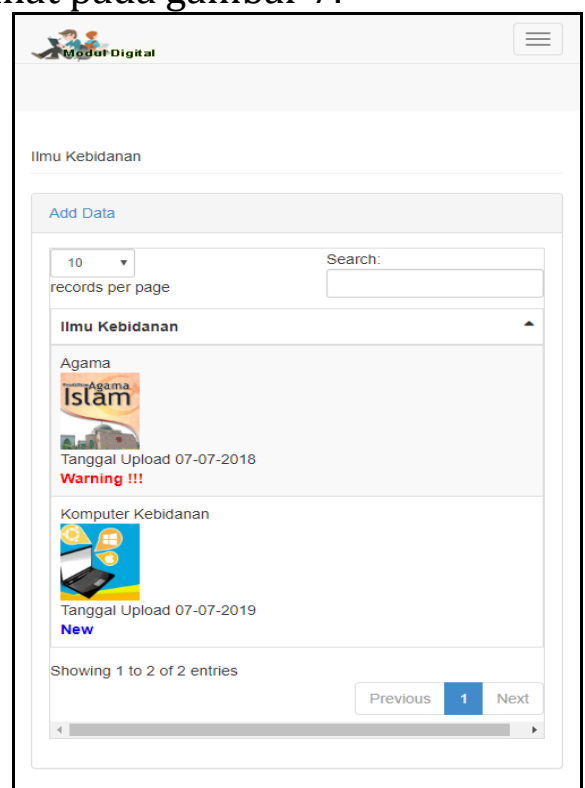

Gambar 7 Daftar modul digital 
e. Detail Modul Digital

Detail modul digital, merupakan pejelasan detail dari modul digital. Interface detail modul digital pada semua user terdiri dari judul modul digital, tanggal upload modul digital, pemberitahuan status modul digital (warning, repair, atau new), diskripsi modul digital, capaian matakuliah, pokok bahasan, dan referensi. Pada detail modul digital pada interface admin terdapat tambahan fasilitas yaitu update modul digital dan delete modul digital. Detail modul digital dapat dilihat pada gambar 8.

f. View modul digital

View modul digital, merupakan tampilan isi modul digital yang dibuka dan dapat dipelajarin menggunakan aplikasi melalui komputer atau smartphone. Tampilan view modul digital dapat dilihat pada gamabr 9

g. Add data

Add data, merupakan merupakan fasilitas yang digunakan untuk meng-input modul digital. Fasilitas add data hanya dapat digunakan gunakan oleh admin dan dosen dalam menambah modul digital. Untuk tampilan add data dapat dilihat pada gambar 10 . 
Kumpulan jurnaL Ilmu Komputer (KLIK)

Volume 06, No.03 Oktober 2019

ISSN: $2406-7857$

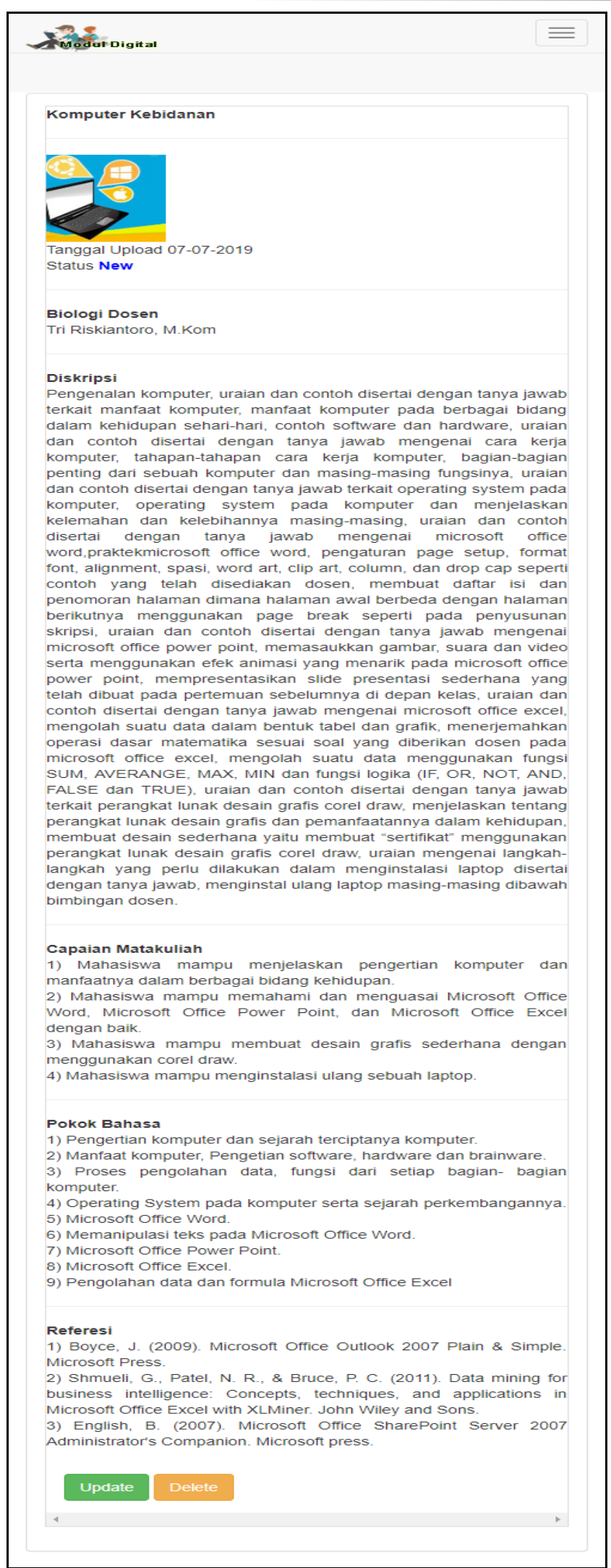

Gambar 8 Detail modul digital 
Kumpulan jurnaL Ilmu Komputer (KLIK)

Volume 06, No.03 Oktober 2019

ISSN: 2406-7857

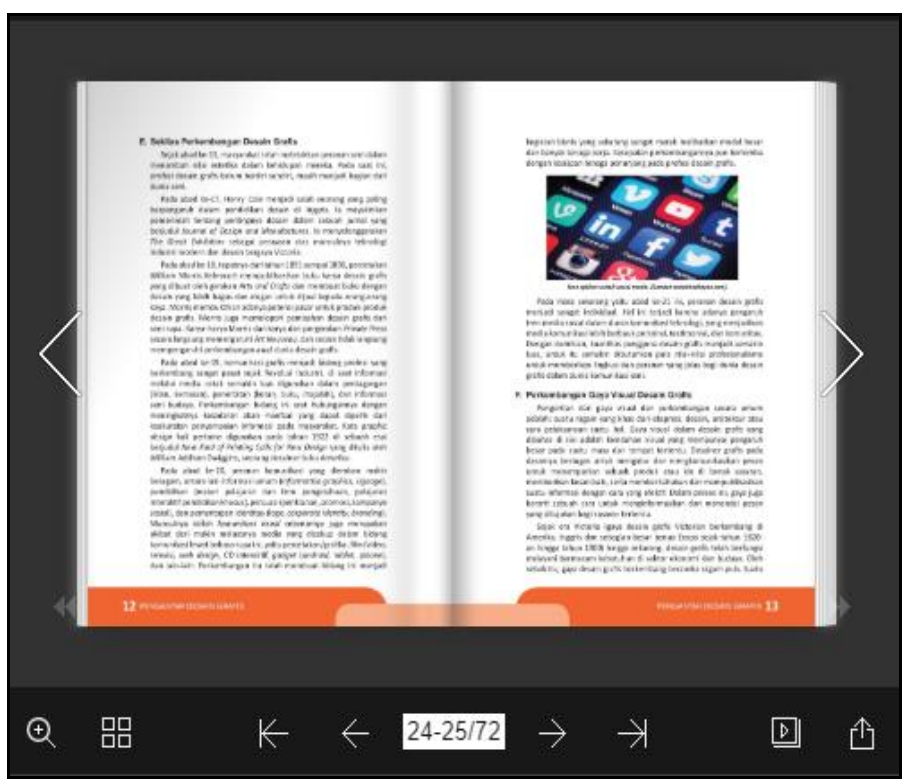

Gambar 9 View modul digital

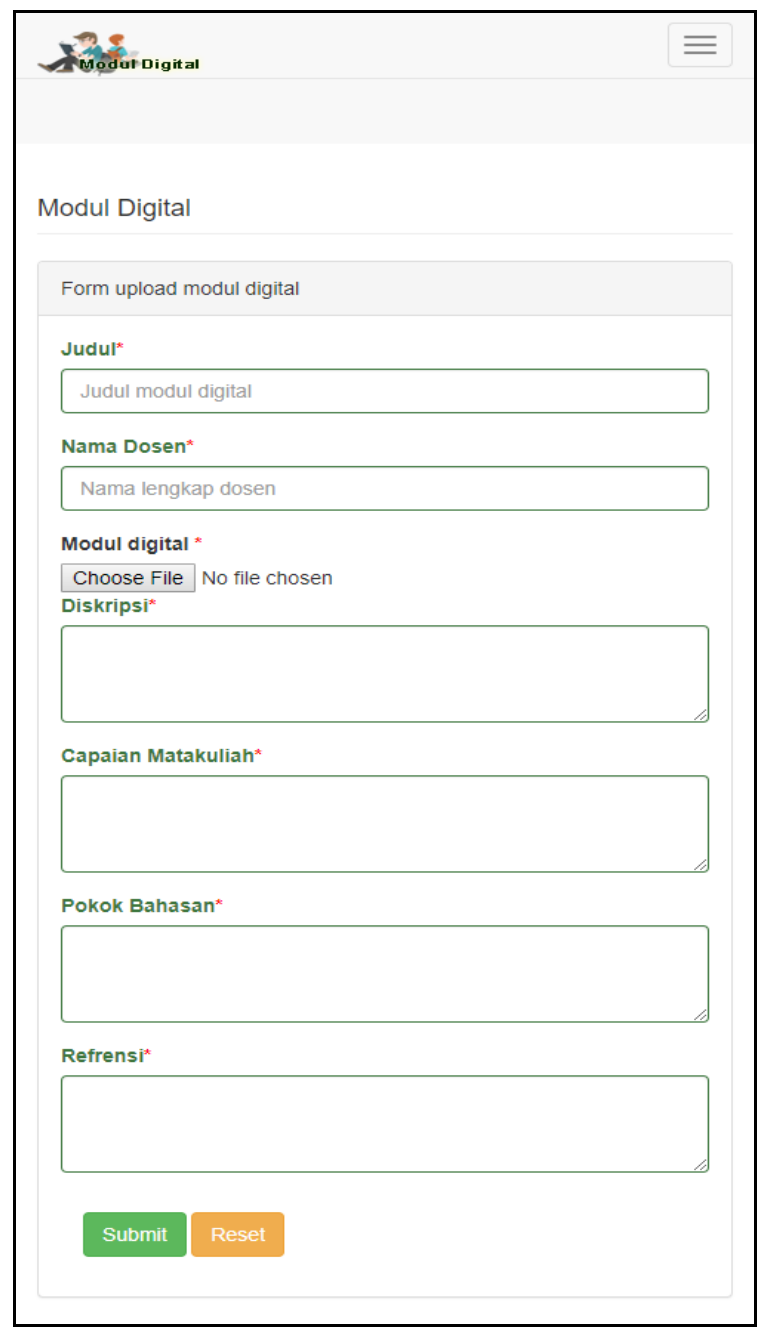

Gambar. 10 add modul digital 


\subsection{Testing Aplikasi Modul Digital Berbasis Web Responsive}

Pengujian interface aplikassi modul digital berbasis web responsive pada STIK Bina Husada Palembang menggunkan blackbox dengan hasil sebagai berikut:

a. Interface Login: halaman login tampil pertama kali ketikan aplikasi modul digital baru diakses, kesimpulan hasil pengujian diterima (tidak error).

b. Interface Dashboard: merupakan halaman utama yang muncul ketika user berhasil melaukan login, user terdiri dari tiga user (admin, dosen, dan mahasiswa), kesimpulan hasil pengujian diterima (tidak error).

c. Interface modul digital: merupakan tampilan daftar dari semua modul digital berdasarkan program studi masing-masing, kesimpulan hasil pengujian diterima (tidak error).

d. Interface detail modul digital: merupakan tampilan penjelasan dari isi modul digital secara garis besar), kesimpulan hasil pengujian diterima (tidak error).

e. Interface view modul digital: merupakan tampilan isi dari buku digital yang dapat dibuka dan dipelajari, kesimpulan hasil pengujian diterima (tidak error).

f. Interface add data: merupakan tampilan halaman yang berfungsi untuk menginputkan modul digital ke aplikasi modul digital berbasis web responsive, kesimpulan hasil pengujian diterima (tidak error).

\section{SIMPULAN}

Penelitian ini menghasilkan modul digital pada STIK Bina Husada berbasis web responsive untuk penunjang dalam proses belajar mengajar. Pada setiap madul digital terdapat penjelasan tentang diskripsi, capai matakuliah, pokok bahasan dan referensi sehingga mahasiswa mengetahui secara garis besar isi modul digital, mahasiswa juga bisa mengetahui apakah modul tersebut baru di-update atau sudah usang. Modul digital ini dikembangkan untuk mempermudah dosen dalam menyampaikan materi dan mempermudah mahasiswa dalam mempelajari materi setiap matakuliah. Pada penelitian selanjutnya agar lebih dikembangkan dengan menambah fitur tambahan pada modul digital seperti soal latihan baik essay dan multiple choice.

\section{DAFTAR PUSTAKA}

[1] I. Solikin, "Implementasi E-Modul pada Program Studi Manajemen Informatika Universitas Bina Darma Berbasis Web Mobile," J. RESTI (Rekayasa Sist. dan Teknol. Informasi), vol. 2, no. 2, pp. 492-497, 2018.

[2] B. K. Williams, S. E. Hutchinson, and S. C. Sawyer, Using information technology: A practical introduction to computers and communications. McGraw-Hill Higher Education, 2001.

[3] N. Hasyim, I. R. Mutiaz, and A. Sachari, "PERANCANGAN DESAIN APLIKASI BUKU DIGITAL (E-BOOK) DENGAN OBJEK MASJID AGUNG DEMAK," Techno. Com, vol. 13, no. 3, pp. 158-167, 2014.

[4] P. W. A. Suyasa, D. G. H. Divayana, and A. Adiarta, "Pemberdayaan teknologi open source dalam pembuatan modul digital bagi para dosen di lingkungan stikes buleleng," WIDYA LAKSANA, vol. 6, no. 2, pp. 120-129, 2017.

[5] I. Solikin and D. Komalasari, "Aplikasi Bahan Ajar Digital pada Sekolah MA. Miftahul Huda Tugu Agung Kab. OKI,” J. Media Inform. dan Komput., vol. 8, no. 
1, pp. 63-69, 2017.

[6] F. Purwaningtias, P. Fitri, and I. Solikin, "Penerapan aplikasi e-book school pada smk emhata Kabupaten ogan komering ilir berbasis web," J. Sist. Informasi, Teknol. Inform. dan Komput., vol. 8, no. 1, pp. 21-30, 2017.

[7] I. Solikin, "PENGEMBANGAN FITUR NOTIFIKASI E-MODUL PADA PROGRAM STUDI MANAJEMEN INFORMATIKA," Simetris J. Tek. Mesin, Elektro dan Ilmu Komput., vol. 10, no. 1, pp. 189-196, 2019.

[8] T. Ramadhan and V. G. Utomo, "Rancang Bangun Aplikasi Mobile untuk notifikasi Jadwal Kuliah Berbasis Android (Studi Kasus STMIK Provisi Semarang)," J. Teknol. Inf. dan Komun., vol. 5, no. 2, pp. 868-2087, 2014.

[9] P. D. Sugiyono, "Metode penelitian kuantitatif dan kualitatif dan R\&D," Bandung Alf., 2008.

[10] M. P. K. Sugiyono, "Cara Mudah Menyusun: Skripsi." Tesis dan Disertasi, Bandung: Alfabeta, 2014.

[11] H. Hasanah, "TEKNIK-TEKNIK OBSERVASI (Sebuah Alternatif Metode Pengumpulan Data Kualitatif Ilmu-ilmu Sosial)," At-Taqaddum, vol. 8, no. 1, pp. 21-46, 2017.

[12] H. Herdiansyah, "Wawancara, observasi, dan focus groups: Sebagai instrumen penggalian data kualitatif," Jakarta PT. Raja Graf. Persada, 2013.

[13] I. Gunawan, "Metode penelitian kualitatif," Jakarta Bumi Aksara, 2013.

[14] R. S. Pressman, "Rekayasa Perangkat Lunak Pendekatan Praktisi (Buku Satu)," Yogyakarta Andi, 2002.

[15] K. Bittner, Use case modeling. Addison-Wesley Longman Publishing Co., Inc., 2002.

[16] M. Muslihudin, Analisis Dan Perancangan Sistem Informasi Menggunakan Model Terstruktur Dan UML. Penerbit Andi, 2016.

[17] S. Hanum, "PEMANFAATAN APLIKASI PENGGAMBAR DIAGRAM ALIR (FLOWCHART) SEBAGAI BAHANAJAR UNTUK MATA KULIAH SISTEM AKUNTANSI DI FAKULTAS EKONOMI PADA PERGURUAN TINGGI SWASTA DI KOTA MEDAN," KITABAH J. Akunt. dan Keuang. Syariah, vol. 1, no. 1, 2017. 